\title{
Repair of an Atherosclerotic Coronary Artery Aneurysm by Implantation of a Coronary Covered Stent
}

\author{
Antenor Portela, Raldir Bastos, Itamar Costa, Jayro Paiva \\ Teresina, PI - Brazil
}

\begin{abstract}
An atherosclerotic aneurysm of the right coronary artery complicated by a recent myocardial infarction was successfully treated with coronary artery stenting, using a device consisting of 2 stents with a layer of expandable polytetrafluorethylene (PTFE) placed between them. A follow-up angiograph 5 months after the procedure showed sustained initial results.
\end{abstract}

Angiographically detected coronary aneurysms secondary to atherosclerosis are relatively uncommon findings ${ }^{1}$. Their natural history is not well defined. Potential complications are rupture, thrombosis, and embolism ${ }^{2}$. They are difficult to treat, and a therapeutic approach to treatment has rarely been described ${ }^{3}$. This is a case of an atherosclerotic coronary artery aneurysm obliterated by a covered stent only recently available on the market.

\section{Case Report}

A 72-year-old woman with typical precordial pain of 2hours duration was admitted to the emergency room. A physical examination showed she was anxious and in considerable distress. Cold perspiration and skin pallor were evident. Her heart rate was 55 beats $/ \mathrm{min}$, while her blood pressure was 100/60 $\mathrm{mmHg}$. Marked elevation of ST-segment existed in the inferior leads. The patient was treated immediately with an intravenous thrombolytic agent (streptokinase 1,500,000 UI). Clinical and electrocardiographic findings indicated that the agent restored vessel patency. The patient had no complications until day 5 when she experienced precordial pain of short duration. Coronary

São Marcos Hospital - Teresina

Mailing address: Antenor Portela - Rua Aviador Irapuan Rocha, 2101 - 64048231 - Teresina, PI - Brazil - E-mail: antenorportela@uol.com.br arteriography revealed moderate hypokinesia in the posterior-basal wall of the left ventricle, left anterior descending and left circumflex coronary arteries without critical lesions and an aneurysm, measuring $6.7 \mathrm{~mm}$ in diameter (measured by Automated Coronary Analysis software for the digital Philips, INTEGRIS H 5000), at the mid portion of the right coronary artery (fig. 1-A). Two tight stenoses were present at the distal and proximal parts of the aneurysm.

The decision to treat with angioplasty and stent implantation in the next few days was made. Administration of $100 \mathrm{mg}$ daily of aspirin was maintained, and $75 \mathrm{mg}$ daily of clopidogrel was started. Two days later, the patient underwent a percutaneous coronary intervention. The guiding catheter used was a JR $48 \mathrm{~F}$ (Cordis, Brite tip) placed through the right femoral artery. After administration of 10,000 IU of heparin, the lesions and the aneurysm were crossed with a 0.014-inch guidewire (standard). Plain balloon angioplasty of the distal lesion was performed with a 3.0x20-mmballoon at an inflation pressure of 8 atmospheres. Subsequently, the more proximal lesion was dilated with a $3.5 \times 20-\mathrm{mm}$ balloon at 10 atmospheres. Then a 2.5-5.0x26-mm covered stent (jostent graft, Jomed, Germany) was hand-crimped on a 3.0x30-mm low-compliance balloon and was deployed at an inflation pressure of 10 atmospheres. Excellent angiographic results were achieved after an additional dilation with a $3.5 \times 20-\mathrm{mm}$ balloon at an inflation pressure of 14 atmospheres (fig. 2). The patient experienced transient hypotension responsive to volume expansion. No distal embolization was observed.

The patient was discharged 2 days after stent implantation on $100 \mathrm{mg}$ of aspirin daily and $75 \mathrm{mg}$ of clopidogrel daily. Clopidogrel was administered for 2 months after the procedure. An exercise stress test performed 4 months after intervention was considered negative for myocardial ischemia. A follow-up coronary angiography performed 5 months after the implantation procedure showed sustained initial results (fig. 3). One year after stenting, the patient remains well and has had no chest pain. 

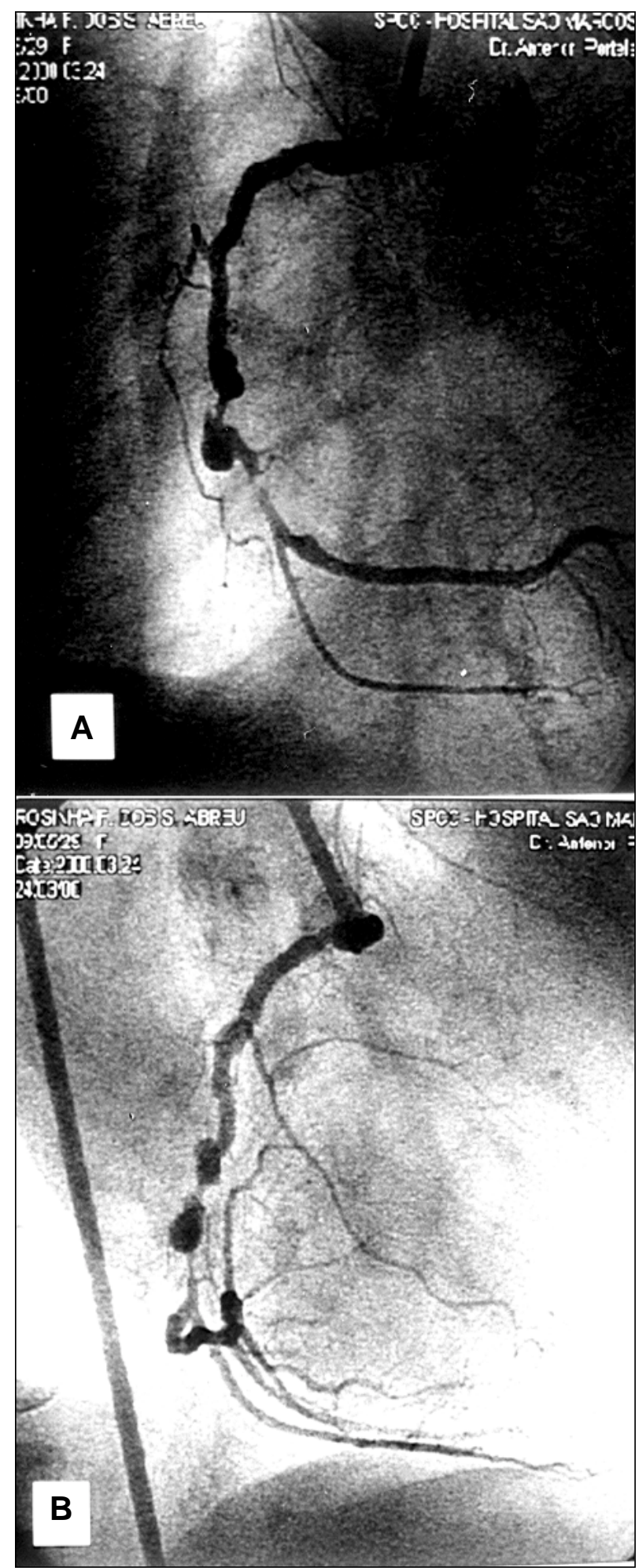

Fig. 1 - A) Right coronary artery (RCA) seen in the left anterior oblique projection (LAO); B) Right coronary artery (RCA) seen in the right anterior oblique projection (RAO).

\section{Discussion}

Atherosclerotic coronary artery aneurysm occurs infrequently and has no known appropriate therapy.
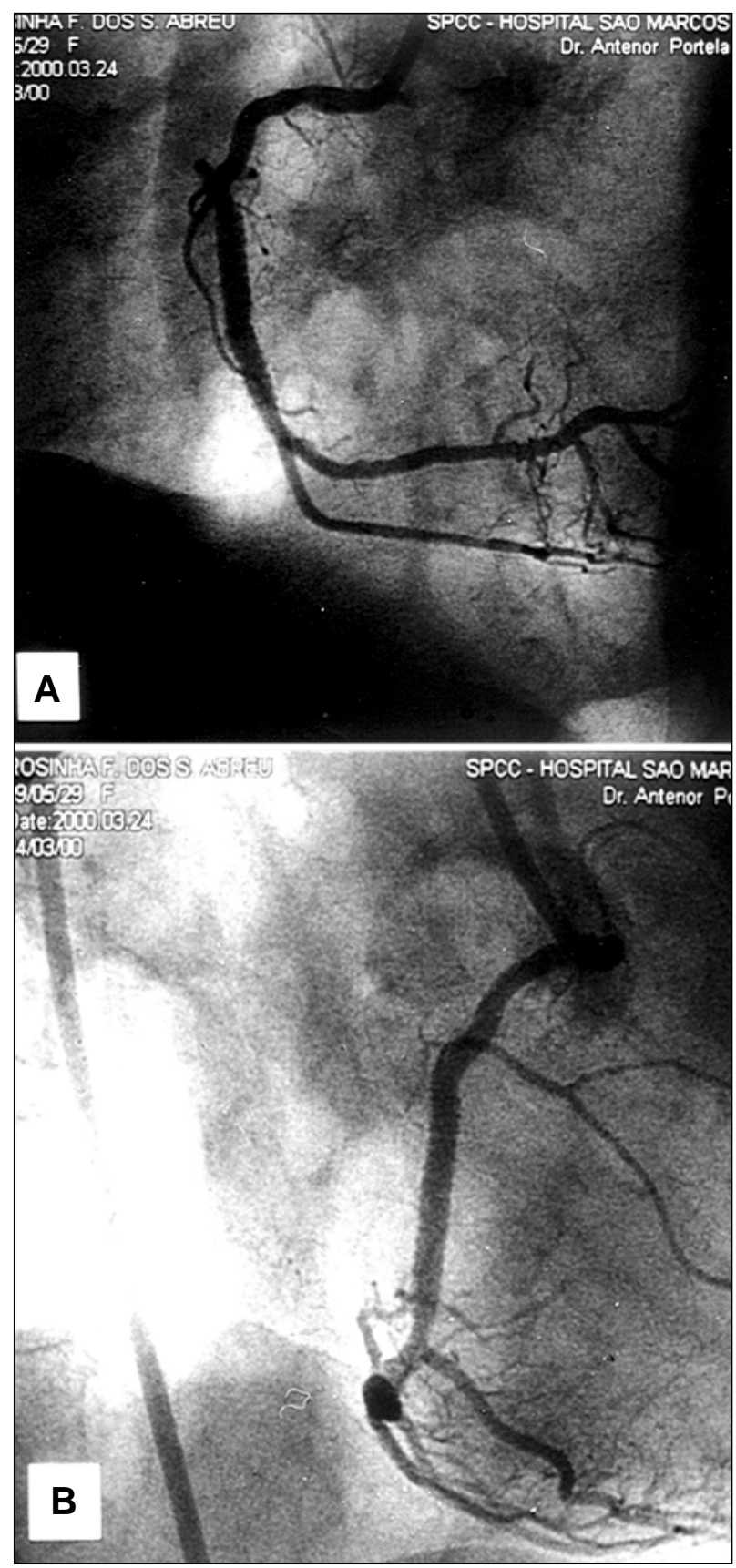

Fig. 2 - A) Right coronary artery (RCA) seen in the anterior oblique projection (LAO); B) right coronary artery (RCA) in the right anterior oblique projection (RAO). Results after stent implantation.

Conservative management has potential complications, such as rupture, tamponade, thrombosis with distal embolization, arterial occlusion, and sudden death ${ }^{4,5}$. Surgery with ligation of the aneurysm and distal bypass is the alternative for high-risk patients ${ }^{6}$. Several reports of percutaneous occlusions of coronary aneurysms have been described recently ${ }^{6}$.

Few cases of coronary artery aneurysm obliteration with PTFE-covered stents have been reported in the literature ${ }^{7-9}$. This is a case study of a patient presenting 

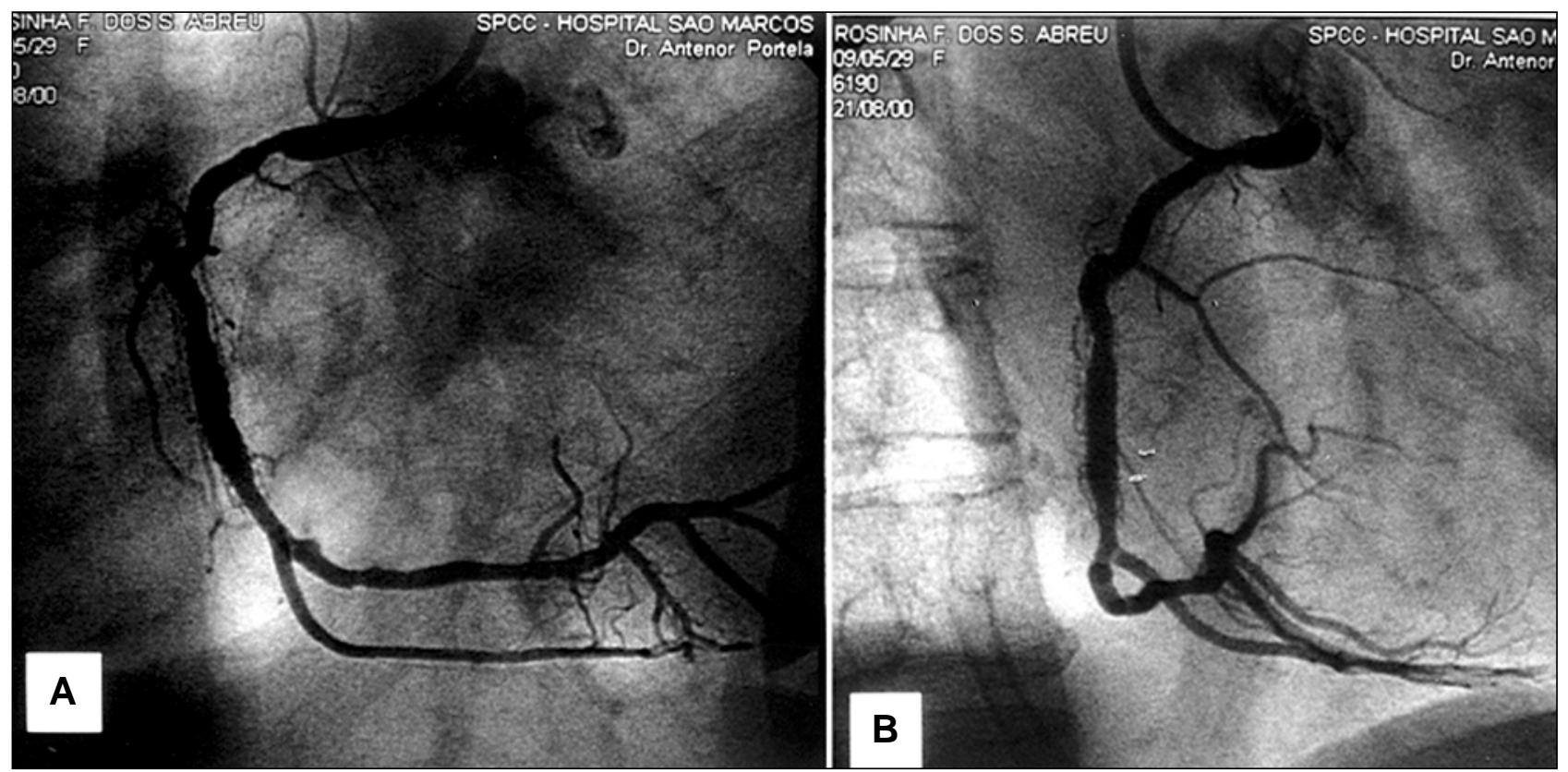

Fig. 3-A) Right coronary artery (RCA) in the left anterior oblique projection (LAO); B) right coronary artery (RCA) in the right anterior oblique projection (RAO). A follow-up coronary angiography 5 months after the implantation procedure.

with a coronary aneurysm and an acute myocardial infarction (AMI). Myocardial infarction and angina are common in patients with coronary ectasia, and the natural history is comparable to that in patients with advanced coronary obstructive disease ${ }^{10}$. The coronary aneurysm had a long neck and could not be obliterated by a noncovered stent in this patient. The novel device, consisting of 2 stents with a layer of expandable graft material resulted in complete exclusion of the aneurysm (fig. 2). In PTFE grafts, a delayed endothelization occurs because its principal mechanism is in-growth from the margins ${ }^{11}$. The clinical significance of atherosclerotic coronary artery aneurysms remains a controversial topic of discussion ${ }^{12,13}$. In this patient, the indication for covering the aneurysm was the proximity of 2 tight coronary stenoses. Sustained angiographic results existed 5 months after intervention. It seems that covered stents offer a viable solution for aneurysm obliteration. Their disadvantages are larger profiles and less flexibility compared with ordinary stents.

\section{References}

1. Swaye PS, Fisher LD,Liwin P, et al. Aneurysmal coronary artery disease. Circulation 1987: 67: 134-8.

2. Swanton RH, Thomas ML, Coltart DJ, Jenkins BS, Webb-Peploe MM, Williams BT. Coronary artery ectasia: a variant of occlusive coronary arteriosclerosis. $\mathrm{Br}$ Heart J 1978; 40: 393-400.

3. Parmar RJ, Uretsky BF. Obliteration of a coronary artery aneurysm with percutaneous transluminal coronary angioplasty and stent placement. Cath Cardiovas Diagn 1997; 41: 51-2.

4. Rath S, Har-Zahav Y, Battler A, et al. Fate of non-obstrutive aneurysmatic coronary artery disease: angiographic and clinical follow-up report. Am Heart J 1985; 109: 785-91.

5. Iga K, Fugikawa T, Ueda Y, etal. Massive hemopericardium as a first manifestation of coronary aneurysm: successful surgical management. Am Heart J 1996; 131 : 618-20.

6. Gruberg L, Grenadier E, Beyar R. Percutaneous closure of a coronary artery aneurysm with a Bare stent. J Invas Cardiol 1999; 11: 141-3.

7. Heuser RR, Woodfield S, Lopez A. Obliteration of a coronary artery aneurysm with a PTFE-covered stent: Endoluminal graft for coronary disease revisited. Cath Cardiovasc Interventions 1999; 46: 113-16.

8. Mario C Di, Imglese L, Colombo A. Treatment of a coronary aneurysm with a new polytetrafluoethulene - coated stent. Cath Cardiovasc Interventions 1999; 46: 463-5.

9. Antonellis IP, Patsilinakos SP, Pamboukas CA, et al. Sealing of coronary artery aneurysm by using a new stent graft. Cath Cardiovasc Interventions 1999; 48 96-9.

10. Markis JE, Joffe CD, Cohn PF, et al. Clinical significance of coronary arterial ectasia. Am J Cardiol 1976; 37: 217-22.

11. Tscuchida H, Wilson SE, Ischimary S. Healing mechanism of high-porosity PTFE grafts: significance of transmural structure. J Surg Res 1197; 71: 187-95.

12. Befeler B, Aramda JM,Embi A, et al. Coronary artery aneurysm: study of their etiology, clinical course and effect on the left ventricular function and prognosis. Am J Med 1977; 62: 597-607.

13. Goudevenos J, Been M, Williams D. Serial angiographic findings during development of saccular aneurysm of the coronary artery in association with unstable angina. Br Heart J 1989; 61: 372-4. 